\title{
Sensitization to cat and dog components and prediction of symptoms in cat-sensitized children
}

\author{
Katarzyna Smejda, Joanna Jerzynska, Daniela Podlecka, Agnieszka Brzozowska
}

\begin{abstract}
Background: Sensitization to cat and/or dog allergens during childhood represents a risk factor for the development of allergic diseases later in life.

Objective: The study investigated the association of patterns of sensitization to cat and dog allergen components with clinical symptoms of allergy to these furry animals among cat-sensitized children.

Methods: The children were evaluated for the presence of bronchial asthma, atopic dermatitis and allergic rhinitis. Their mothers completed a questionnaire on pet exposure at home. Levels of serum IgE cat epitopes Fel d (1, 2, 4), as well as dog components Can $\mathrm{f}(1,2,3,5)$ were measured in all the studied children.

Results: Respiratory symptoms following exposure to the cat allergen were most common in children with Fel d 2 epitope $(p=0.041)$. After contact with a dog, respiratory symptoms were most common in children with Can $\mathrm{f} 1$ epitope $(p=0.042)$, atopic dermatitis in children with sensitization to both Can $\mathrm{f} 1(p=0.009)$ and Can $\mathrm{f} 2(p=0.002)$, whereas eye symptoms occurred mostly in children with Can f $3(p=0.039)$.
\end{abstract}

Conclusion: Molecular diagnosis in patients with pet allergy may help clinicians to predict clinical symptoms and their severity.

Key words: children, components, cat, dog, allergy, symptoms, sensitization

\section{From:}

Department of Pediatrics and Allergy, Medical University of Lodz, Copernicus Memorial Hospital in Lodz, Poland

\author{
Corresponding author: \\ Joanna Jerzynska \\ Department of Pediatrics and Allergy, Medical University of Lodz, \\ Poland, Copernicus Memorial Hospital, Korczak Pediatric Center, \\ Piłsudskiego 71 Str., 90-329 Lodz, Poland \\ E-mail: alergol@kopernik.lodz.pl
}

\section{Introduction}

Cats and dogs are the most common household pets. According to the latest research, over half (52\%) of households in Poland own a pet. Forty-two percent of Polish citizens declare that they have a dog, 26\% report to keep a cat, and 5\% possess other animals. ${ }^{1}$ In the ECAP study of the Polish population, an average frequency of cat allergy was $13.5 \%$, and in the case of dog allergy it was $9.7 \% .^{2}$ The dog and cat allergens are a common cause of allergic sensitization and a factor triggering respiratory symptoms worldwide.

Molecule-based diagnosis of allergy is an important advancement in improving sensitivity and specificity. ${ }^{3}$ The major cat allergen, in up to $96 \%$ cases, is Fel d 1, a uteroglobin produced in the skin and salivary glands. ${ }^{4,5,6}$ Other important cat allergens are albumin of Fel d 2 serum, ${ }^{7}$ and lipocalin Fel d 4, ${ }^{8}$ which cross-reacts with the corresponding proteins from other animals. ${ }^{9}$ Commonly described dog allergens represent lipocalins (Can f 1, Can f 2, Can f 4 and Can f 6) or albumins (Can f 3$){ }^{10}$ prostatic kallicrein (Can f 5) which is an androgen-regulated protein expressed in the prostate and detectable only in male dogs. ${ }^{11}$ Due to the low degree of sequence identity among them, lipocalins were considered as species-specific allergy markers.

Sensitization to Fel $\mathrm{d} 1$ and Can $\mathrm{f} 1$ in childhood and polysensitization to either cat or dog allergen molecules predict allergy significantly better than cat or dog IgE extracts. ${ }^{12}$ Fel d 7 is a common allergen in the cat-sensitized population that cross-reacts with Can $\mathrm{f} 1$ and may contribute to symptoms in both cat-allergic and dog-allergic patients. ${ }^{13}$ 
The study investigated the association of patterns of sensitization to cat and dog allergen components with clinical symptoms of allergy to these furry animals among cat-sensitized children, considering their prenatal/postnatal exposure to the pets.

\section{Methods}

The study included 50 children of both sexes, aged 5-17 years, patients of our allergy clinic, seen between January and September of 2018, who showed sensitization to cat allergen based on the skin prick test. They were considered to have allergy to cat if they suffered from one or more allergy symptoms when exposed to contact with a cat, which was confirmed by positive medical history. The allergy was manifested among others by ocular symptoms (tearing, redness, pruritus), nasal symptoms (sneezing, nasal itch, runny nose), eczema, symptoms of the lower respiratory tract (cough, shortness of breath, wheezing). The children were also evaluated for the presence of bronchial asthma, atopic dermatitis, and allergic rhinitis. The current child health status assessment was performed by an allergist at the study visit. The definition of asthma used was based on the Global Initiative for Asthma (GINA) guidelines (www.ginaasthma.org). Atopic dermatitis was diagnosed according to the revised Hanifin and Rajka criteria (https://dermnetnz.org/topics/guidelines-for-the -diagnosis-and-assessment-of-eczema/). The diagnosis of AR was performed according to ARIA guidelines (https://www. ncbi.nlm.nih.gov/pmc/articles/PMC7066682/).

Their mothers completed a questionnaire on pet exposure at home: a) during pregnancy, b) in the first two years of the child's life, and c) after the second year of the child's life. Since a majority of the mothers reported having a dog rather than a cat, additional analyses of sensitization to dog allergens were performed. Children were considered to have allergy to dog if they suffered from one or more allergy symptoms that occurred when having contact with a dog, and at the same time presented Can f level $(1,2,3$ or 5$)$ of least grade 1.

Blood samples were collected from all the studied children to measure the IgE serum levels for the cat epitopes, Fel d 1, Fel d 2, Fel d 4, as well as for the dog components, Can f 1, Can f 2, Can f 3, Can f 5. IgE serum levels > 0.35 IU/ $\mathrm{ml}$ were regarded as a positive result. The serum samples were analyzed for IgE antibodies using the ImmunoCAP ${ }^{\circledR}$ system according to the manufacturer's guidelines (Phadia AB, Uppsala, Sweden). Serum samples of venous blood were used. The samples were stored at $-20^{\circ} \mathrm{C}$. The ImmunoCAP Specific IgE detects IgE antibodies in the range from 0 to $100 \mathrm{kUA} / \mathrm{l}$ where "A" stands for allergen-specific antibodies. The result is read quantitatively. In clinical practice, a level of $0.35 \mathrm{kUA} / 1$ has commonly been accepted as a cut-off. The clinical performance is expressed as sensitivity, ranging from $84 \%$ to $95 \%$, and specificity, ranging from $85 \%$ to $94 \%$.

The study was approved by the Bioethics Committee of the Medical University of Lodz, Poland, RNN/39/14/KE; a written informed consent was obtained from all the subjects before the assays.

\section{Statistical analysis}

The investigated traits were described based on the measures of location - arithmetic or geometric mean, along with measures of dispersion - standard deviation, 95\% confidence interval as well as minimum and maximum values. The categorical variables were depicted by using absolute numbers and percentages.

Multivariate logistic regression models (for binary dependent variables such as allergy symptoms or having an animal at home) were performed in order to test statistical relationships. When dealing with non-normally distributed variables, robust standard errors (i.e. sandwich estimators) were used within a specific regression model. Some variables, which revealed the perfect prediction (i.e., when each study participant or none of them displayed a specific trait), were excluded from a regression equation. All the regression models were controlled for the studied patients' age and gender. A level of $P<0.05$ was considered statistically significant. All the statistical computations were carried out by means of Stata/Special Edition, release 14.2 (StataCorp LP, College Station, Texas, USA).

\section{Results}

Baseline characteristics of the studied population are presented in Table 1.

\section{Cat allergen components and allergy symptoms}

Thirty-eight children were allergic to cats as determined by positive anamnesis, whereas twelve patients exhibited clinically non-relevant sensitization as indicated by negative anamnesis (Table 1). Forty-seven of all the children (94.00\%) had at least one of the Fel d epitopes tested, 34 children had only one epitope (72.34\%), eight children had two epitopes (17.02\%), four children had three epitopes (8.51\%). There was no relationship between the number of epitopes and symptoms of allergy to cats. The most common epitope was Fel d 1 (90\% of the whole study group); relevant results are displayed in Figure 1. Respiratory symptoms following contact with a cat allergen were most frequent in the children with Fel d 2 epitope $(p=0.041)$ (Table 2$)$. There was no relationship between other (i.e., ocular, nasal, cutaneous) symptoms of allergy to cats and the type of epitope (Table 2). A correlation was found between the occurrence of Fel d 2 epitope and any symptoms appearing after contact with a cat $(p=0.048)$ (Table 2).

\section{Dog allergen components and allergy symptoms}

Twelve children were allergic to dogs as confirmed by positive anamnesis and thirty-eight exhibited clinically non-relevant sensitization as indicated by negative anamnesis (Table 1). Twenty nine of the fifty study participants $(58.00 \%)$ had at least one of the Can $\mathrm{f}$ epitopes tested, sixteen children had only one epitope (55.17\%), ten children had two epitopes $(34,48 \%)$, one patient had three epitopes $(3.45 \%)$, and one child had four epitopes (3.45\%). There was no relationship between the number of epitopes and symptoms of allergy to dogs. The most common epitope was Can $\mathrm{f} 1$ (32\% of the study sample); the results are shown in Figure 1. 
Table 1. Baseline characteristics of the studied patients ( $n$ =50)

\begin{tabular}{|c|c|c|}
\hline \multirow{2}{*}{ Investigated trait } & \multicolumn{2}{|c|}{ Statistical parameter } \\
\hline & $\mathbf{M}$ & SD \\
\hline Age (years) & 11.7 & 3.32 \\
\hline & $\mathbf{n}$ & $\%$ \\
\hline Gender (female) & 18 & 36.0 \\
\hline Symptoms after contact with the cat & 38 & 76.0 \\
\hline Symptoms after contact with the dog & 12 & 24.0 \\
\hline Keeping a cat in any period of life & 16 & 32.0 \\
\hline Keeping a dog in any period of life & 26 & 52.0 \\
\hline Presence of other pets & 7 & 14.0 \\
\hline Asthma & 45 & 90.0 \\
\hline Allergic rhinitis & 50 & 100.0 \\
\hline Atopic dermatitis & 6 & 12.0 \\
\hline Symptoms after contact with a cat & 38 & 76.0 \\
\hline Ocular & 31 & 62.0 \\
\hline Nasal & 32 & 64.0 \\
\hline In the lower airway (Asthma) & 10 & 20.0 \\
\hline Atopic dermatitis & 12 & 24.0 \\
\hline Symptoms after contact with a dog & 12 & 76.0 \\
\hline Ocular & 4 & 8.0 \\
\hline Nasal & 7 & 14.0 \\
\hline In the lower airways (Asthma) & 5 & 10.0 \\
\hline Atopic dermatitis & 7 & 14.0 \\
\hline
\end{tabular}

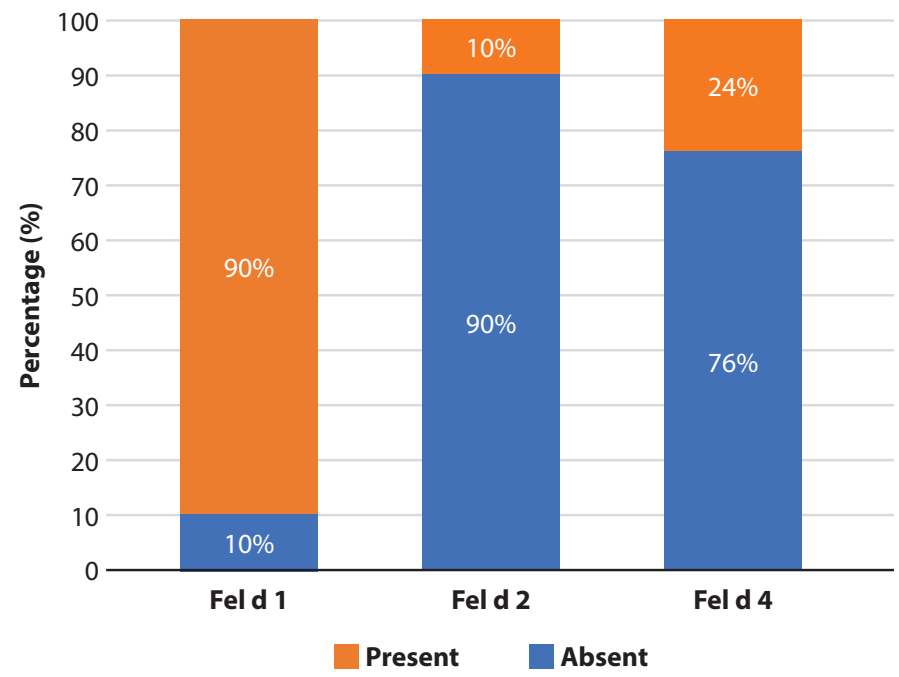

Figure 1. Presence of selected epitopes - referring to allergy to cat dander - in the studied patients $(n=50)$

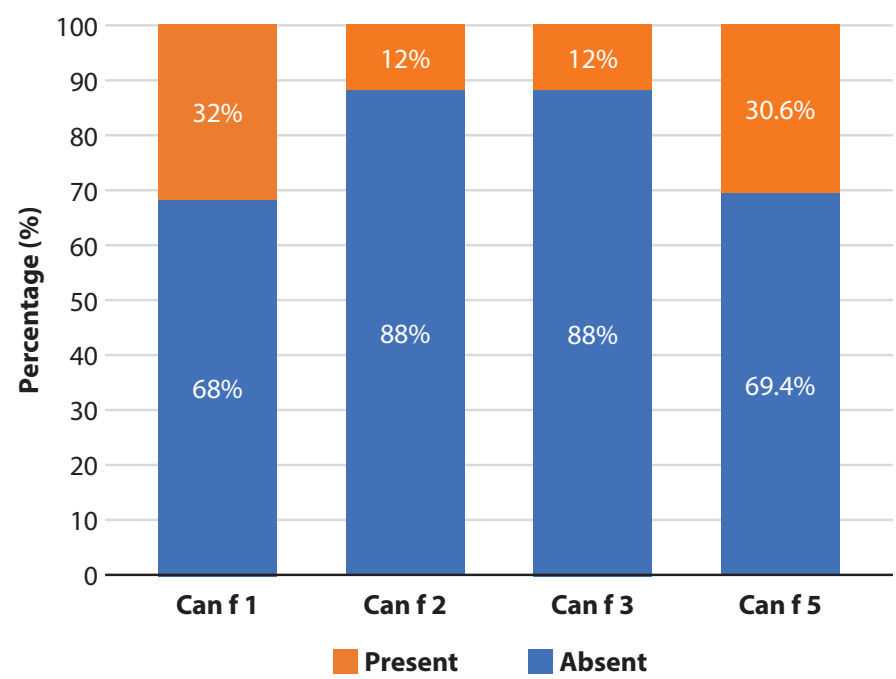

Figure 2. Presence of selected epitopes - referring to allergy to dog dander - in the studied patients $(n=50)$

Table 2. Allergic symptoms after contact with a cat/dog and the prevalence of selected Fel d and Can $\mathrm{f}$ epitopes in the studied patients $(n=50)$

\begin{tabular}{|c|c|c|c|c|c|c|c|c|c|}
\hline $\begin{array}{l}\text { Allergic symptoms after contact } \\
\text { with the pet }\end{array}$ & Fel d 1 & Fel d 2 & Fel d 4 & $\begin{array}{l}\text { TOTAL } \\
\mathbf{n},(\%)\end{array}$ & Can $\mathrm{f} 1$ & Can $\mathrm{f} 2$ & Can $\mathrm{f} 3$ & Can f 5 & $\begin{array}{l}\text { TOTAL } \\
\text { n, }(\%)\end{array}$ \\
\hline Any symptoms & $\begin{array}{l}35,(92.1) \\
p=0.377\end{array}$ & $\begin{array}{l}4,(10.5) \\
p=0.048\end{array}$ & $\begin{array}{l}8,(21.1) \\
p=0.385\end{array}$ & $38,(76.0)$ & $\begin{array}{l}9,(75.0) \\
p=0.001\end{array}$ & $\begin{array}{l}4,(33.3) \\
p=0.036\end{array}$ & $\begin{array}{l}3,(25.0) \\
p=0.280\end{array}$ & $\begin{array}{c}4,(33.3) \\
p=0.942\end{array}$ & $12,(24.0)$ \\
\hline Ocular & $\begin{array}{l}29,(93.6) \\
p=0.550\end{array}$ & $\begin{array}{c}3,(9.7) \\
p=0.923\end{array}$ & $\begin{array}{l}7,(22.6) \\
p=0.764\end{array}$ & $31,(62.0)$ & $\begin{array}{l}3,(75.0) \\
p=0.173\end{array}$ & $\begin{array}{c}0,(0.00) \\
p=0.812\end{array}$ & $\begin{array}{l}2,(50.0) \\
p=0.039\end{array}$ & $\begin{array}{c}1,(25.0) \\
p=0.733\end{array}$ & $4,(8.0)$ \\
\hline Nasal & $\begin{array}{l}29,(90.6) \\
p=0.844\end{array}$ & $\begin{array}{c}3,(9.4) \\
p=0.844\end{array}$ & $\begin{array}{l}7,(21.9) \\
p=0.639\end{array}$ & $32,(64.0)$ & $\begin{array}{l}7,(100.0) \\
p=0.008\end{array}$ & $\begin{array}{l}2,(28.6) \\
p=0.408\end{array}$ & $\begin{array}{l}2,(28.6) \\
p=0.385\end{array}$ & $\begin{array}{l}3,(42.9) \\
p=0.722\end{array}$ & $7,(14.0)$ \\
\hline In the lower airways (Asthma) & $\begin{array}{l}10,(100.0) \\
p=0.426\end{array}$ & $\begin{array}{l}3,(30.0) \\
p=0.041\end{array}$ & $\begin{array}{l}3,(30.0) \\
p=0.650\end{array}$ & $10,(20.0)$ & $\begin{array}{c}4,(80.0) \\
p=0.063\end{array}$ & $\begin{array}{c}2,(40.0) \\
p=0.192\end{array}$ & $\begin{array}{c}2,(40.0) \\
p=0.206\end{array}$ & $\begin{array}{c}2,(40.0) \\
p=0.952\end{array}$ & $5,(10.0)$ \\
\hline Atopic dermatitis & $\begin{array}{l}11,(91.7) \\
p=0.825\end{array}$ & $\begin{array}{c}2,(16.7) \\
p=0.377\end{array}$ & $\begin{array}{c}3,(25.0) \\
p=0.926\end{array}$ & $12,(24.0)$ & $\begin{array}{c}6,(85.7) \\
p=0.009\end{array}$ & $\begin{array}{c}4,(57.1) \\
p=0.002\end{array}$ & $\begin{array}{c}2,(28.6) \\
p=0.192\end{array}$ & $\begin{array}{c}3,(42.9) \\
p=0.695\end{array}$ & $7,(14.0)$ \\
\hline TOTAL n, (\%) & $45,(90.0)$ & $5,(10.0)$ & $12,(24.0)$ & $50,(100.0)$ & $16,(32.0)$ & $6,(12.0)$ & $6,(12.0)$ & $15,(30.0)$ & $50,(100.0)$ \\
\hline
\end{tabular}


Table 3. Overlapping of selected Fel $d$ and/or Can $f$ epitopes in the studied patients $(n=50)$

\begin{tabular}{|cccccccc}
\hline Epitope & Fel d 1 & Fel d 2 & Fel d 4 & Can f 1 & Can f 2 & Can f 3 & Can f 5 \\
\hline Fel d 1 & & 4 & 11 & 15 & 6 & 5 & 13 \\
\hline Fel d 2 & 4 & & 5 & 3 & 1 & 5 & 1 \\
\hline Fel d 4 & 11 & 5 & & 6 & 4 & 5 & 2 \\
\hline Can f 1 & 15 & 3 & 6 & & 6 & 1 & 6 \\
\hline Can f 2 & 6 & 1 & 4 & 6 & & 1 & 2 \\
\hline Can f 3 & 5 & 5 & 5 & 3 & 1 & & 1 \\
\hline Can f 5 & 13 & 1 & 3 & 6 & 2 & 1 & \\
\hline
\end{tabular}

Table 4. Keeping a cat or a dog in the domicile and prevalence of selected Fel $d$ and Can f epitopes in the studied patients, respectively $(\mathbf{n}=50)$

\begin{tabular}{|c|c|c|c|c|c|c|c|c|c|}
\hline Keeping a cat/a dog & Fel d 1 & Fel d 2 & Fel d 4 & $\begin{array}{l}\text { TOTAL } \\
\mathbf{n},(\%)\end{array}$ & Can $\mathrm{f} 1$ & Can $\mathbf{f} 2$ & Can $\mathrm{f} 3$ & Can $\mathrm{f} 5$ & $\begin{array}{c}\text { TOTAL } \\
\mathbf{n},(\%)\end{array}$ \\
\hline Overall & $\begin{array}{c}14,(87.5) \\
p=0.69\end{array}$ & $\begin{array}{l}2,(12.5) \\
p=0.69\end{array}$ & $\begin{array}{l}4,(25.0) \\
p=0.81\end{array}$ & $16,(32.0)$ & $\begin{array}{l}12,(46.2) \\
p=0.033\end{array}$ & $\begin{array}{l}5,(19.2) \\
p=0.23\end{array}$ & $\begin{array}{l}3,(11.5) \\
p=0.92\end{array}$ & $\begin{array}{l}9,(34.6) \\
p=0.40\end{array}$ & $26,(52.0)$ \\
\hline During pregnancy & $\begin{array}{c}6,(100.0) \\
p=0.70\end{array}$ & $\begin{array}{l}1,(16.7) \\
p=0.89\end{array}$ & $\begin{array}{l}1,(16.7) \\
p=0.95\end{array}$ & $6,(12.0)$ & $\begin{array}{c}8,(53.3) \\
p=0.042\end{array}$ & $\begin{array}{l}3,(20.0) \\
p=0.26\end{array}$ & $\begin{array}{c}1,(6.7) \\
p=0.82\end{array}$ & $\begin{array}{l}7,(46.7) \\
p=0.11\end{array}$ & $15,(30.0)$ \\
\hline Once in the past & $\begin{array}{c}14,(87.5) \\
p=0.92\end{array}$ & $\begin{array}{l}2,(12.5) \\
p=0.62\end{array}$ & $\begin{array}{l}4,(25.0) \\
p=0.87\end{array}$ & $16,(32.0)$ & $\begin{array}{l}12,(46.2) \\
p=0.033\end{array}$ & $\begin{array}{l}5,(19.2) \\
p=0.23\end{array}$ & $\begin{array}{l}3,(11.5) \\
p=0.92\end{array}$ & $\begin{array}{l}9,(34.6) \\
p=0.40\end{array}$ & $26,(52.0)$ \\
\hline At the age of $0-2$ & $\begin{array}{l}8,(88.9) \\
p=0.62\end{array}$ & $\begin{array}{l}1,(11.1) \\
p=0.71\end{array}$ & $\begin{array}{l}2,(22.2) \\
p=0.77\end{array}$ & $9,(18.0)$ & $\begin{array}{c}9,(50.0) \\
p=0.048\end{array}$ & $\begin{array}{l}3,(16.7) \\
p=0.47\end{array}$ & $\begin{array}{l}2,(11.1) \\
p=0.89\end{array}$ & $\begin{array}{l}7,(38.9) \\
p=0.24\end{array}$ & $18,(36.0)$ \\
\hline At the age of over 2 & $\begin{array}{c}11,(84.6) \\
p=0.83\end{array}$ & $\begin{array}{c}1,(7.7) \\
p=0.91\end{array}$ & $\begin{array}{l}3,(23.1) \\
p=0.77\end{array}$ & $13,(26.0)$ & $\begin{array}{l}12,(48.0) \\
p=0.021\end{array}$ & $\begin{array}{l}5,(20.0) \\
p=0.19\end{array}$ & $\begin{array}{l}3,(12.0) \\
p=1.00\end{array}$ & $\begin{array}{l}9,(36.0) \\
p=0.31\end{array}$ & $25,(50.0)$ \\
\hline Currently & $\begin{array}{l}8,(80.0) \\
p=0.56\end{array}$ & $\begin{array}{l}1,(10.0) \\
p=0.81\end{array}$ & $\begin{array}{l}2,(20.0) \\
p=0.93\end{array}$ & $10,(20.0)$ & $\begin{array}{l}9,(47.4) \\
p=0.13\end{array}$ & $\begin{array}{l}4,(21.1) \\
p=0.12\end{array}$ & $\begin{array}{l}3,(15.8) \\
p=0.52\end{array}$ & $\begin{array}{l}6,(31.6) \\
p=0.91\end{array}$ & $19,(38.0)$ \\
\hline $\begin{array}{l}\text { TOTAL } \\
\mathrm{n},(\%)\end{array}$ & $45,(90.0)$ & $5,(10.0)$ & $12,(24.0)$ & $50,(100.0)$ & $16,(32.0)$ & $6,(12.0)$ & $6,(12.0)$ & $15,(30.0)$ & $50,(100.0)$ \\
\hline
\end{tabular}

Atopic dermatitis developing after contact with a dog showed a strong relationship with sensitization to both Can $\mathrm{f} 1$ ( $p=$ $0.009)$ and Can f $2(p=0.002)$ allergen components (Table 2). The presence of allergic symptoms in the eyes showed a significant relationship with sensitization to Can $\mathrm{f} 1$ and Can $\mathrm{f} 3$ ( $p=0.042$ and $p=0.039$, respectively) (Table 2 ). Additionally, the presence of Can $\mathrm{f} 1$ and Can $\mathrm{f} 2$ significantly conditioned the occurrence of atopic dermatitis after contact with a dog ( $p=0.009$ and $p=0.002$, respectively) (Table 2 ).

\section{Pet components and allergic disorders}

Monosensitization to Can $\mathrm{f} 1$ significantly underpinned the prevalence of atopic dermatitis in the studied children $(p=0.036)$.

\section{Cross-reactivity}

Table 3 depicts the co-occurrence of selected Fel d and/or Can $\mathrm{f}$ epitopes in the studied children. Fifteen children $(30 \%)$ showed sensitivity to Fel $\mathrm{d} 1$ and Can $\mathrm{f} 1$, whereas thirteen patients $(26 \%)$ to Fel d 1 and Can f 5.

\section{Prenatal/postnatal exposure to pets}

Keeping a cat during pregnancy, in early childhood, or at any time during a child's life showed no relationship to sensitization to any feline epitopes tested. Having a dog in any period of pre-natal and post-natal life was associated with sensitization to Can $\mathrm{f} 1$ epitope $(p=0.033)$ (Table 4). Keeping a dog and a cat at the same time - regardless of the life stage, prenatal or postnatal, did not reveal any statistically significant relationship with sensitization to the epitopes tested.

\section{Discussion}

In the last few years, component resolved diagnostics (CRD) has been developing rapidly, and both singleplex and multiplex assays are used in relation to over one hundred recombinant or purified native allergen components. ${ }^{14}$ Molecular allergy is based on identification, characterization and subsequent use of single allergens, being components of complex allergen sources like pollen, mites, furred animals, foods or insect venoms. ${ }^{15,16,17}$ Thus, carefully defined allergen molecules serve as a useful complement to the reagents available to date, and optimize IgE determination and detection of specific sensitization in the context of allergy diagnosis..$^{16,17}$ 
Our study showed that respiratory symptoms after contact with a cat and a dog have a strong relationship with presence of Fel d 2 components, respectively. The occurrence of atopic dermatitis after contact with a dog reveals a strong association with the presence of Can $\mathrm{f} 1$ and Can $\mathrm{f} 2$ epitopes. The presence of ocular symptoms showed a significant relationship with Can $\mathrm{f} 1$ and Can $\mathrm{f} 3$ epitope.

Gent at al. found that the risk for wheezing in children sensitized and exposed to pet allergen significantly increased. ${ }^{18}$ In our study there was statistically significant relationship between diagnosed asthma and sensitization to Fel d 2. The most frequent symptoms of cat owners suffering from allergy when exposed to contact with their pets were rhinitis and conjunctivitis, less often cutaneous symptoms, and lower respiratory symptoms. Dog owners with allergy to their pets suffered from cutaneous symptoms more frequently than cat owners with cat allergy, especially in terms of urticaria as well as from lower respiratory symptoms, especially cough. ${ }^{19}$ In our study, symptoms occurred more frequently in people who were allergic after contact with a cat. After contact with a cat, our patients most often showed symptoms of allergic rhinitis and conjunctivitis, wheras after contact with a dog, the most common symptoms were allergic rhinitis and atopic dermatitis.

In our study, monosensitization to Can $\mathrm{f} 1$ was related to the diagnosis of atopic dermatitis. Uriarte at al. showed that Can $\mathrm{f} 1$ was associated with persistent rhinitis, Can $\mathrm{f} 2$ with asthma diagnosis, Can $\mathrm{f} 3$ with severity of rhinitis and asth$\mathrm{ma}$, and Can $\mathrm{f} 5$ both to persistence and severity of rhinitis. Sensitization to several allergens in patients $(1,2,3$ or 4$)$ was associated with persistent moderate asthma or rhinitis. Direct contact with dogs was connected both with persistence and severity of rhinitis. ${ }^{20,21}$ Fel d 2 was associated with severity of rhinitis and asthma. Fel d 4 was associated with the presence of asthma symptoms. Direct contact with cats was associated both with persistence and severity of rhinitis. ${ }^{22}$ Bjerg et al. reported a higher prevalence of asthma in children co-sensitized to Fel $\mathrm{d} 1$ and Fel d 4 than in children sensitized to Fel d 1 alone. ${ }^{23}$ They also found a higher prevalence of asthma (55\%) in patients with IgE reactivity, not only towards Fel $\mathrm{d} 1$, but also towards Fel d 2 and/or rFel d 4. Wisniewski et al. described an association between high levels of $\operatorname{IgE}$ antibodies to $\mathrm{nFel} \mathrm{d} 2$ and $\mathrm{rFel} \mathrm{d} 4$ and atopic dermatitis in cat-allergic children. ${ }^{24}$ In our study, as many as $90 \%$ of patients were diagnosed with bronchial asthma. While respiratory symptoms following contact with a cat allergen were most frequent only in the children with Fel d 2 epitope. We found no association between lower respiratory symptoms and having any epitope for the dog allergen. We also did not show any association between allergic rhinitis and having any dog or cat epitope tested.

The exposure to animal allergens constitutes a relevant risk factor for the development of allergic sensitization. Some authors suggest that early contact with dogs, before the first year of age, may have a protective effect in terms of allergic sensitizations. ${ }^{25}$ Similarly, conflicting studies have been reported for early cat exposures. ${ }^{26}$ So far, no consensus has been reached on the potential association between animal exposure and prevention of onset of asthma or other allergic diseases in later life. ${ }^{27}$ Conclusions presented in various studies also differ on the impact of canine or feline allergens as being those most protective ones. ${ }^{28}$ In our study, keeping a dog at any time, in any period of prenatal and postnatal life, was associated with the occurrence of IgE to Can $\mathrm{f} 1$ epitope and allergy symptoms. While our study has not shown any relationship between keeping a cat during pregnancy, in early childhood, or at any time during a child's life, keeping a cat during pregnancy had no relation to the occurrence of any of the cat epitopes tested either. Many authors have found no relationship between possession of animals and exposure to asthma and other allergic diseases. ${ }^{29,30}$ In a meta-analysis of eleven European birth cohorts including $>22$ thousand children, there was no relationship between keeping any furry animal (mainly a cat and $\mathrm{dog}$ ) at home in the first two years of a child's life and occurrence of asthma at 6-10 years of age. ${ }^{31}$ However, there are very reliable studies that suggest a protective effect of having a pet. Takkouche et al. showed that exposure to dogs slightly increased the risk of asthma, but exposure to cats played a protective role. ${ }^{32}$ Researchers from Sweden found that keeping a dog in the first year of a child's life is associated with a significantly lower risk of asthma in children aged 6 years. ${ }^{33}$ Another study, involving 696 Swedish children, reports that current asthma and asthma symptoms following contact with cats were associated with cosensitization to Fel d 1 and Fel d 4. Asthma was related to higher levels of component sensitization (Fel d $1 \geq 15$ ISU) while sensitization to more than one component from the same animal conferred the greatest risk. ${ }^{34}$ Based on the evidence form the past decade it may be assumed that early exposure to dogs before the first year of life may have a protective effect in preventing allergic sensitizations. ${ }^{35}$

The limitation of our study is the small sample size and a restricted number of assayed components. All the studied children were diagnosed with allergic rhinitis, which is why the disease was not included in multifactor statistical analyses.

\section{Conclusions}

To sum up, our article described the pattern of sensitization to pet IgE components and its association with clinical symptoms. Our study showed that respiratory symptoms in children allergic to cats or dogs demonstrate a strong relationship with the presence of Fel d 2 components, respectively. Eczema after contact with a dog showed a strong correlation with the presence of Can f 1 and Can f 2 epitopes. The presence of allergic eye symptoms showed a statistically significant relationship with the presence of the Can $\mathrm{f} 1$ and the Can $\mathrm{f} 3$ epitope. However, Fel d 1 is the most important cat allergen component, yet the functional role of this molecule remains unknown. Molecular diagnosis in patients with allergy to pets may help clinicians to predict clinical symptoms and their severity.

\section{Conflict of interest}

The authors declare no conflict of interest regarding publication of this article. 


\section{Financial}

This study was funded by grant 503/2-056-01/503-21-001 from the Medical University of Lodz, Poland.

\section{References}

1. Kantar Public - Social Research Team. Zwierzęta w polskich domach. May 2017, K.021/17.

2. Sybilski AJ, Raciborski F, Lipiec A, Tomaszewska A, Lusawa A, Samel -Kowalik P, et al. Epidemiology of atopic dermatitis in Poland according to the Epidemiology of Allergic Disorders in Poland (ECAP) study. J Dermatol. 2015;42(2):140-7.

3. Canonica GW, Ansotegui IJ, Pawankar R, Schmid-Grendelmeier P, van Hage M, Baena-Cagnaniet CE, et al. A WAO - ARIA - GA ${ }^{2} L E N$ consensus document on molecular-based allergy diagnostics. World Allergy Organ J. 2013;6:17.

4. Kaiser L, Velickovic TC, Badia-Martinez D, Adedovin J, Thunberg S, Hallen $\mathrm{D}$, et al. Structural characterization of the tetrameric form of the major cat allergen Fel d 1. J Mol Biol. 2007;370:714-27.

5. Bonnet B, Messaoudi K, Jacomet F, Michaud E, Fauquert JL, Caillaud D, et al. An update on molecular cat allergens: Fel d 1 and what else? Chapter 1: Fel d 1, the major cat allergen. Allergy Asthma Clin Immunol. 2018; 14: 14.

6. van Ree R, van Leeuwen WA, Bulder I, Bond J, Aalberse RC. Purified natural and recombinant Fel $\mathrm{d} 1$ and cat albumin in in vitro diagnostics for cat allergy. J Allergy Clin Immunol. 1999;104:1223-30.

7. Virtanen T, Kinnunen T. Mammalian allergens. Clin Allergy Immunol. 2008;21:201-18.

8. Smith W, Butler AJ, Hazell LA, Chapman MD, Pomés A, Nickels DG, et al. Fel d 4, a cat lipocalin allergen. Clin Exp Allergy. 2004;34:1732-8.

9. Hilger C, Swiontek K, Arumugam K, Lehners C, Hentges F. Identification of a new major dog allergen highly cross-reactive with Fel $\mathrm{d} 4$ in a population of cat- and dog-sensitized patients. J Allergy Clin Immunol. 2012;129(4):1149-51.

10. Hentges F, Leonard C, Arumugan K, Hilger C. Immune response to mammalian allergens. Front Immunol. 2014;21;5:234.

11. Mattsson L, Lundgren T, Everberg H, Larsson H, Lidholm J. Prostatic kallikrein: A new major dog allergen. J Allergy Clin Immunol. 2009;123: 362-8.

12. Patelis A, Dosanjh A, Gunnbjörnsdottir M, Borres MP, Högman M, Alving $\mathrm{K}$, et al. New data analysis in a population study raises the hypothesis that particle size contributes to the pro-asthmatic potential of small pet animal allergens. Ups J Med Sci. 2016;121:25-32

13. Apostolovic D, Sánchez-Vidaurre S, Waden K, Curin M, Grundström J, Gafvelin G,et al. The cat lipocalin Fel d 7 and its cross-reactivity with the dog lipocalin Can f 1. Allergy. 2016;71(10):1490-5.

14. Kleine-Tebbe J, Jakob T. Molecular allergy diagnostics using IgE singleplex determinations: methodological and practical considerations for use in clinical routine: Part 18 of the Series Molecular Allergology. Allergo J Int. 2015;24:185-97.

15. Kleine-Tebbe J, Jappe U. Molecular allergy diagnostic tests: development and relevance in clinical practice. Allergol Select. 2017 Aug 4;1(2):169-89.

16. Cui Y, Yu L, Teng F, Wang N, Zhou Y, Zhang C, et al. Expression of recombinant allergen, Der f 1 , Der f 2 and Der f 4 using baculovirus-insect cell systems. Arch Med Sci. 2018;14(6):1348-54.
17. Petrosino MI, Scaparrotta A, Marcovecchio ML, Panichi D, Rapino $\mathrm{D}$, Attanasi $\mathrm{M}$, et al. Usefulness of molecular diagnosis in egg allergic children. Arch Med Sci. 2018;14(1):132-7.

18. Gent JF, Kezik JM, Hill ME, Tsai E, Li DW, Leaderer BP. Household mold and dust allergens: exposure, sensitization and childhood asthma morbidity. Environ Res. 2012;118:86-93

19. Yang MS, Lee SP, Kwon YJ, Lee SM. Dog and Cat Allergies and Allergen Avoidance Measures in Korean Adult Pet Owners Who Participated in a Pet Exhibition. Allergy Asthma Immunol Res. 2018; 10(2): 155-64.

20. Uriarte SA, Sastre J. Clinical relevance of molecular diagnosis in pet allergy. Allergy. 2016;71(7):1066-8.

21. Uriarte SO, Sastre J. Clinical impact of molecular diagnosis in dog allergy Clin Transl Allergy. 2014; 4(Suppl 2): P52.

22. Uriarte SO, Sastre J. Clinical impact of molecular diagnosis in cat allergy. Clin Transl Allergy. 2014; 4(Suppl 2): P51.

23. Bjerg A, Winberg A, Berthold M, Mattsson L, Borres MP, Rönmark E. A population-based study of animal component sensitization, asthma and rhinitis in schoolchildren. Pediatr Allergy Immunol. 2015;26(6):557-63.

24. Wisniewski JA, Agrawal R, Minnicozzi S, Xin W, Patrie J, Heymann PW, et al. Sensitization to food and inhalant allergens in relation to age and wheeze among children with atopic dermatitis. Clin Exp Allergy. 2013; 43(10):1160-70.

25. Takkouche B, González-Barcala FJ, Etminan M, Fitzgerald M. Exposure to furry pets and the risk of asthma and allergic rhinitis: a meta-analysis. Allergy. 2008;63:857-64

26. Celedón JC, Litonjua AA, Ryan L, Platts-Mills T, Weiss ST, Gold DR Exposure to cat allergen, maternal history of asthma, and wheezing in first 5 years of life. Lancet. 2002;360:781-2.

27. Flohr C, Yeo L. Atopic dermatitis and the hygiene hypothesis revisited. In: Shiohara T, editor. Pathogenesis and management of atopic dermatitis Basel: Karger; 2011. pp. 1-34.

28. Mandhane PJ, Sears MR, Poulton R, Greene JM, Lou WY, Taylor DR, et al Cats and dogs and the risk of atopy in childhood and adulthood. J Allergy Clin Immunol. 2009; 124:745-50.

29. Chen CM, Tischer C, Schnappinger M, Heinrich J. The role of cats and dogs in asthma and allergy - a systematic review. Int J Hyg Environ Health. 2010;213:1-31

30. Medjo B, Atanaskovic-Markovic M, Nikolic D, Spasojevic-Dimitrijeva B Ivanovski P, Djukic S. Association between pet-keeping and asthma in school children. Pediatr Int. 2013;55:133-7.

31. Lødrup Carlsen KC, Roll S, Carlsen KH, Mowinckel P, Wijga AH Brunekreef B, et al. Does pet ownership in infancy lead to asthma or allergy at school age? Pooled analysis of individual participant data from 11 European birth cohorts. PLoS One. 2012;7:e43214.

32. Takkouche B, González-Barcala FJ, Etminan M, Fitzgerald M. Exposure to furry pets and the risk of asthma and allergic rhinitis: a meta-analysis. Allergy. 2008;63:857-64.

33. Fall T, Lundholm C, Örtqvist AK, Fall K, Fang F, Hedhammar Å, etal. Early Exposure to Dogs and Farm Animals and the Risk of Childhood Asthma. JAMA Pediatr. 2015;169:e153219.

34. Bjerg A, Winberg A, Berthold M, Mattsson L, Borres MP, Rönmark E. A population-based study of animal component sensitization, asthma, and rhinitis in schoolchildren. Pediatr Allergy Immunol. 2015;26:557-63.

35. Takkouche B, González-Barcala FJ, Etminan M, Fitzgerald M. Exposure to furry pets and the risk of asthma and allergic rhinitis: a meta-analysis. Allergy. 2008;63:857-64. 